EXTENDED REPORT

\title{
Reduced functional performance in the lower extremity predicted radiographic knee osteoarthritis five years later
}

\author{
C A Thorstensson, I F Petersson, L T H Jacobsson, T L Boegård, E M Roos
}

Ann Rheum Dis 2004;63:402-407. doi: 10.1136/ard.2003.007583

See end of article for authors' affiliations

Correspondence to: Dr C Thorstensson Spenshult Hospital for Rheumatic Diseases, Oskarström, Sweden, S-313 92: carina.thorstensson@ spenshult.se

Accepted 14 June 2003
Background: Reduced quadriceps strength is an early finding in subjects with knee osteoarthritis, but it is not clear whether it is a cause or a consequence of knee osteoarthritis.

Objective: To determine whether reduced functional performance in the lower extremity predicts the incidence or progression of radiographic knee osteoarthritis.

Design: Prospective, epidemiological, population based cohort study.

Patients: 148 subjects (62 women), aged 35-54 (mean 44.8), with chronic knee pain from a population based cohort.

Measurements: Predictors analysed were age, sex, body mass index, baseline knee pain, and three tests of lower extremity functional performance: maximum number of one-leg rises from sitting, time spent walking $300 \mathrm{~m}$, and timed standing on one leg. Weightbearing tibiofemoral knee radiographs were obtained at baseline and after 5 years (median 5.1, range 4.2-6.1), and classified according to Kellgren and Lawrence as no osteoarthritis (Kellgren and Lawrence $=0, n=94$ ) or prevalent osteoarthritis (Kellgren and Lawrence $\geqslant 1, n=54$ ).

Results: Fewer one-leg rises (median $17 \vee 25$ ) predicted incident radiographic osteoarthritis five years later (OR 2.6, 95\% Cl 1.1 to 6.0). The association remained significant after controlling for age, sex, body mass index, and pain. No significant predictor of radiographic progression in the group with prevalent osteoarthritis was found.

Conclusion: Reduced functional performance in the lower extremity predicted development of radiographic knee osteoarthritis 5 years later among people aged 35-55 with chronic knee pain and normal radiographs at baseline. These findings suggest that a test of one-leg rises may be useful, and interventions aimed at improving functional performance may be protective against development of knee osteoarthritis. l: is estimated that approximately $5 \%$ of the population aged between 35 and 55 years have radiological findings of knee osteoarthritis. ${ }^{1-5}$ These changes range from the presence of only osteophytes in the early stages up to joint space obliteration. The Kellgren and Lawrence grading system is widely used to classify radiographic osteoarthritis. ${ }^{6}$ It might be argued that Kellgren and Lawrence grade 1 (minute osteophytes, doubtful significance) should not really be considered as osteoarthritis, because it is of limited clinical importance and the relevance of osteophytes in the osteoarthritic process is not clear. However, Hart and Spector recently showed that Kellgren and Lawrence grade 1 is clearly associated with progression of radiographic features 5 years later, and therefore should be treated as an early phase of the disease. ${ }^{7}$

Little evidence concerning reliable predictors of osteoarthritis development and prognosis for individual subjects is available. The development of incident osteoarthritis and the progression of prevalent osteoarthritis do not necessarily have the same risk factors. ${ }^{8}$

Reduced quadriceps strength is a finding associated with symptomatic knee osteoarthritis, but the cause of weakness is not clear. Suggested explanations include age, disuse atrophy due to pain and decrease in physical activity, ${ }^{9}$ and weakness as a result of articular damage. ${ }^{10}$ Alternatively, reduced quadriceps strength may be a cause and not a consequence of osteoarthritis. ${ }^{11}$ Reduced muscle strength may result in relative articular instability and functional "micro-clutziness", ${ }^{12}$ and increased joint load. ${ }^{13}$

This study aimed at identifying the predictive value of three tests of lower extremity functional performance, controlled for age, sex, body mass index, and baseline pain, for the development of radiographic knee osteoarthritis 5 years later in a population based cohort of middle aged subjects with chronic knee pain.

\section{METHODS}

\section{Subjects}

In 1990 a questionnaire was sent to 2000 randomly selected people aged 35-54 (963 women and 1037 men) in a district in the south west of Sweden, with a mixed urban and rural population, to estimate the prevalence of chronic knee pain. Chronic knee pain was defined as "pain in either of your knees practically daily for the past three months". One thousand eight hundred and fifty three people (93\%) answered the questionnaire, of whom 279 (15\%) reported chronic knee pain. Those who had chronic knee pain were offered a radiographic and a clinical examination, ${ }^{5}$ and 204 agreed to participate. One hundred and fifty two subjects were available for follow up five years later (fig l). Because this study concerns the development of radiographic knee osteoarthritis, we decided to exclude four patients owing to diverging radiographic features in the right and left knee at follow up. These four patients each had one knee that had become worse and one that had become better. This made it difficult to determine whether they had progressed or not. Thus 148 subjects constituted the cohort of the present study. Table 1 describes the patient characteristics.

Ethical approval was obtained from the ethics committee, Medical Faculty, Lund University. 


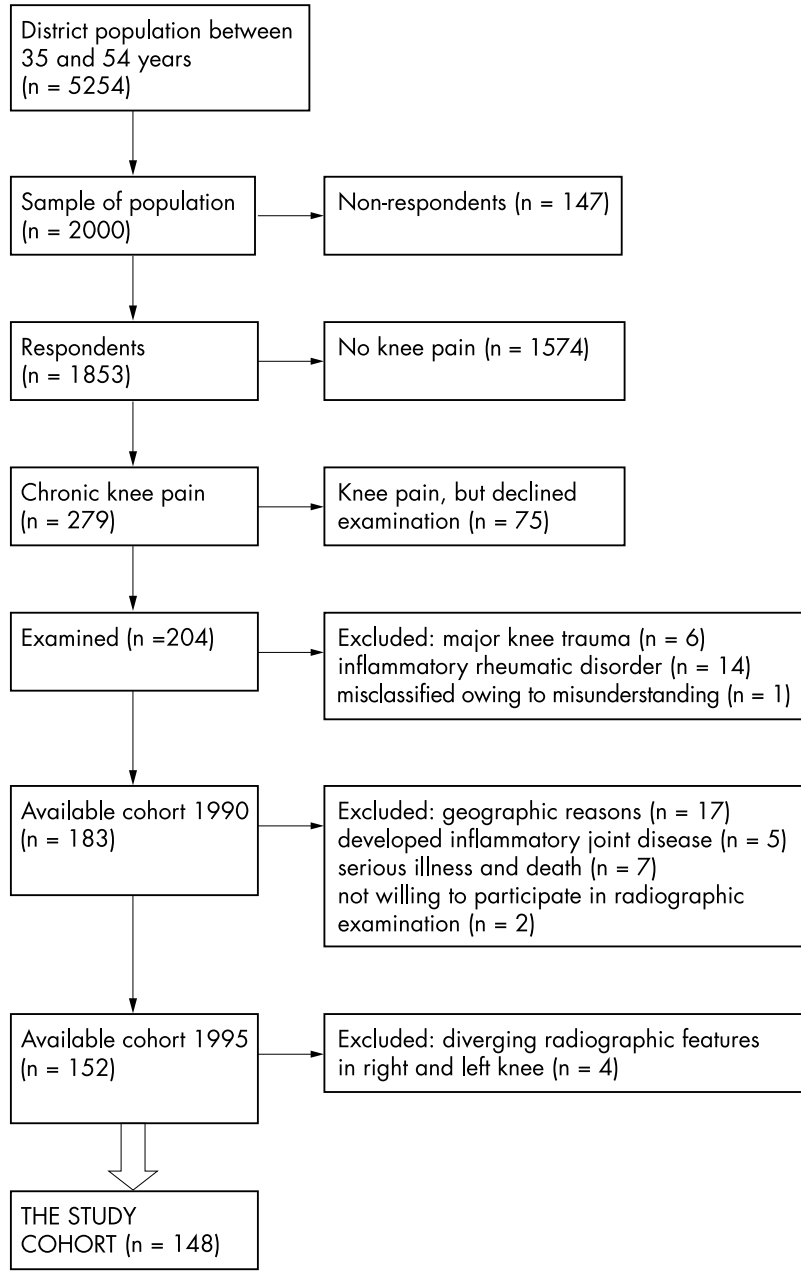

Figure 1 Flow from sample of population at baseline to study cohort at follow up.

\section{Baseline examinations}

Tests of functional performance

A trained physiotherapist recorded the functional performance of the lower extremities. These tests, which have been described earlier, ${ }^{14}$ were:

- Maximum number of one-leg rises from sitting on a stool $(0.48 \mathrm{~m})$. The patient was instructed how to perform the test, and told to place one foot on the floor in a self chosen position. One attempt was allowed, and thereafter the foot position was not to be changed during the test. The lifted leg was held with straight knee, and arms were hanging along the body. The test should be performed with full muscle control-that is, the sitting down phase should be performed at constant speed and the uprising phase without adding arm or trunk movement. A pause of 5 minutes was prescribed between the right and left leg. The numbers of adequately performed rises were counted.

- Time spent walking 300 metres indoors, including one turn around. An indoor corridor was used for the test. A line on the floor marked start and stop, and another line at the other end of the corridor had to be passed before turning around. The patients were told to walk as fast as they could without running, to start on the command "ready, steady, go", and to keep up the speed past the stop line. ${ }^{15}$ Time was measured in minutes and seconds using an analogue stopwatch. Patients answered the question "How much pain do you have in your knees right now?" by putting a mark on a visual analogue scale (VAS) just before and straight after the test of time spent walking.

- Timed standing on one leg with simultaneous, rapid repeated neck rotations, with eyes open and arms hanging along the body (modification of the test used by Ekdahl et al ${ }^{16}$ ). Time spent on one leg, without any support, was measured in seconds using an analogue stopwatch. When the lifted foot touched the floor, when support was needed, or after 30 seconds, which was considered "normal", the test was interrupted. One attempt was allowed.

\section{Radiographic and clinical examination}

Posteroanterior radiographs of both tibiofemoral joints were obtained with straight knees in the weightbearing position and with the weight equally distributed on both legs. The medial aspects of the feet were aimed to be parallel with each other. The central $x$ ray beam was horizontal and aimed at the level of the centre of the popliteal fossa, and the right and left knees were reproduced by the same exposure.

The medical history was obtained and a rheumatologist made a clinical examination. Height and weight were recorded, and body mass index was calculated as $\mathrm{kg} / \mathrm{m}^{2}$. Patients with disorders, other than osteoarthritis, known to cause knee pain were identified and excluded from further analysis (fig l).

\section{Follow up}

Radiographic examination

After 5 years (median 5.1, range 4.2-6.1) posteroanterior radiographs of both tibiofemoral joints were obtained in weight bearing in a fluoroscopy unit. The patients stood with almost the entire weight on the examined leg, with the knee flexed $30-50^{\circ}$, and with the patella and the big toe touching the table of the fluoroscopy unit. The medial aspect of the foot was parallel to the central $x$ ray beam, and the beam was adjusted to be tangential to the anterior and posterior aspect of the medial tibial condyle.

The baseline radiographs and the radiographs at the follow up were classified according to Kellgren and Lawrence ${ }^{6}$ by an experienced radiologist (TLB). The baseline radiographs and the radiographs at the follow up were evaluated on different occasions and the reader was unaware of the name and the age of the patient and the results from other examinations and tests. The intraobserver agreement for re-reading the baseline radiographs has been evaluated previously, ${ }^{5}$ showing high agreement $(\kappa=0.88)$. The inter- and intraobserver variation for minimum joint space and osteophytes in the semiflexed position varied from 0.72 to $0.98 .^{17}{ }^{18}$ Kellgren and Lawrence grade 1 was defined as prevalent osteoarthritis. ${ }^{7}{ }^{18}$ A change of one grade or more according to Kellgren and Lawrence was defined as progression. ${ }^{7} 19$ The index knee was set as the knee with radiographic signs of progression at follow up for those who had radiographic changes in only one knee. If two knees were affected to different grades, the knee with the worst progression at follow up became the index knee, and for those who had no radiographic changes (Kellgren and Lawrence $=0$ ), or equal changes in both knees, the right or left knee was randomly assigned as the index knee.

\section{Statistics}

Statistical testing was performed using SPSS 10.0 for Windows. Analyses were conducted using non-parametric tests. ${ }^{20}$ Calculations were made using data from the index knee only. Because progression was influenced by increased grade of radiographic changes at baseline, as determined by the Kruskal-Wallis test $(p=0.05)$, we decided to analyse two 
Table 1 Group characteristics for the total study cohort and the two subgroups with (a) no radiographic signs of osteoarthritis at baseline (no $O A$ ) and (b) prevalent $O A$ at baseline (OA)

\begin{tabular}{|c|c|c|c|c|c|c|c|}
\hline \multirow[b]{2}{*}{ Group } & \multirow[b]{2}{*}{$\mathrm{n}^{*}$} & \multirow{2}{*}{$\begin{array}{l}\text { Aget } \\
\text { (years) }\end{array}$} & \multirow{2}{*}{$\begin{array}{l}\text { Female } \\
\text { No }(\%)\end{array}$} & \multirow{2}{*}{$\begin{array}{l}\text { BMIई } \\
\left(\mathrm{kg} / \mathrm{m}^{2}\right)\end{array}$} & \multirow{2}{*}{$\begin{array}{l}\text { Progression बा } \\
\text { No }(\%)\end{array}$} & \multicolumn{2}{|c|}{$\begin{array}{l}\text { Kellgren and Lawrence grade } \\
0 / 1 / 2 / 3 / 4(n)\end{array}$} \\
\hline & & & & & & Baseline & Follow up \\
\hline All & 148 & $45(35-54)$ & $62(42)$ & $25.3(18.3-37.5)$ & $70(47)$ & & \\
\hline No OA & 94 & $45(35-54)$ & $39(41)$ & $25.3(18.3-37.0)$ & $41(44)$ & $94 / 0 / 0 / 0 / 0$ & $53 / 33 / 4 / 3 / 1$ \\
\hline & 54 & $45.5(35-54)$ & $23(43)$ & $25.6(20.2-37.5)$ & $29(54)$ & $0 / 36 / 9 / 9 / 0$ & $8 / 13 / 12 / 12 / 9$ \\
\hline
\end{tabular}

*Number of patients included; tage at baseline, median (range); łnumber (\%) women of total selection; §body mass index at baseline, median (range); - number (\%) of patients with progression of radiographic changes at follow up (Kellgren and Lawrence $\geqslant 1$ grade).

groups separately: those with no radiographic changes at baseline and those with prevalent knee osteoarthritis at baseline (table 1). Firstly, the risk of developing incident radiographic knee osteoarthritis or progression of already existing knee osteoarthritis was determined for the two groups separately. The median value of each predictor was used to dichotomise the predictor variable into a category variable, with values above or below the median. Logistic regression was used to determine the odds ratio of progression of radiographic features 5 years later. To determine whether those whose radiographic changes had regressed differed from the remaining cohort, the Mann-Whitney U test was used. Spearman's test was used to determine covariation between predictors.

\section{Role of the funding source}

The study sponsors had no role in the study design, in the collection, analysis, or interpretation of the data, or in the writing and publication of the report.

\section{RESULTS}

\section{No osteoarthritis at baseline (table 1)}

Forty one of 94 patients (44\%) developed incident osteoarthritis. The test of the maximum number of one-leg rises from sitting at baseline significantly predicted development of incident knee osteoarthritis 5 years later (median $17 v 25$ times, table 2). Age, sex, body mass index, and baseline pain did not predict incident osteoarthritis. The impact of fewer one-leg rises on the development of incident osteoarthritis at follow up remained significant even when controlling for age, sex, body mass index, and baseline pain one by one (table 3 ). The number of adequately performed one-leg rises, time spent walking, and timed standing on one leg were not significantly associated with baseline pain.

\section{Prevalent osteoarthritis at baseline (table 1)}

The radiographic status progressed in 29/54 (54\%) patients. None of the variables analysed could explain the radiographic progression of already existing knee osteoarthritis, although where progression occurred patients tended to have higher body mass index, perform fewer one-leg rises, and manage a shorter time standing on one leg (table 4). Controlling the three tests of lower extremity functional performance for age, sex, body mass index, and pain did not change the results (data not shown). Radiographic features of 11 patients had regressed at follow up (table 1). A comparison of characteristics between them and the remaining cohort showed that they had a lower body mass index $\left(23.4 \vee 25.5 \mathrm{~kg} / \mathrm{m}^{2}\right.$, $\mathrm{p}=0.05)$.

\section{DISCUSSION}

\section{Main message}

This study supports the hypothesis that limitations in lower extremity functional performance can predict radiographic knee osteoarthritis. ${ }^{11}$ In this study cohort of subjects reporting knee pain before baseline examination we found that reduced functional performance in the lower extremities is an early sign of knee osteoarthritis, detectable before radiographic changes appear, and that reduced functional performance may in fact even be causative. Pain intensity in the knee on the day of examination did not affect functional performance, as measured with the tests in this study. The maximum number of one-leg rises from sitting, the test that significantly predicted radiographic osteoarthritis, may be of importance in the early identification of subjects who have poor prognosis. By directing preventive treatments, it might be possible to delay, or perhaps prevent, the development and the consequences of osteoarthritis. ${ }^{21}$

\section{Comparison with other studies}

Our results suggest that tests of lower extremity functional performance are valuable in predicting incident osteoarthritis. None of the factors analysed in this study could explain progression, and it has been suggested that different risk factors might influence the incidence and progression of osteoarthritis. ${ }^{8}$ Incidence in this study is chiefly defined as development of osteophytes, while progress is chiefly defined by joint space narrowing. Our decision to perform separate analyses of prevalent and incident cases was based on the fact that progress is influenced by increased radiographic changes at baseline. Recent studies have shown that existing radiographic changes due to osteoarthritis are strong predictors of progression, ${ }^{722}$ which supports our decision. It has previously been shown that quadriceps strength did affect the incidence of knee osteoarthritis, ${ }^{11}$ but not the progression of radiographic changes in elderly subjects with existing knee osteoarthritis. ${ }^{23}$ Our findings pointed in the expected direction. In the group with prevalent osteoarthritis, there was a trend towards worse functional performance and higher body mass index among those with radiographic progression. It is well known that being overweight is a risk factor for developing incident knee osteoarthritis, ${ }^{24}{ }^{25}$ but in the present study, body mass index was not associated with the development of osteoarthritis in the group with normal radiographs at baseline. Possible explanations for this include chance or that the majority of cases analysed developed osteophytes and not joint space narrowing. Further follow up may be needed to show how many of these go on to develop joint space narrowing, for which body mass index may be a stronger predictor. The median body mass index $\left(25.2 \mathrm{~kg} / \mathrm{m}^{2}\right)$ in the group developing incident knee osteoarthritis in the present study was just above what is considered normal. However, in our study those whose radiographic changes regressed turned out to have a lower body mass index than those who had stable or progressive radiographic changes. Also worth noticing is the fact that the median age of this cohort was about 10 years younger than, for instance, the women in the Chingford study. ${ }^{24}$ 
Table 2 In the group with no radiographic changes at baseline, less endurance in oneleg rise from sitting predicted incident osteoarthritis (OA) 5 years later. Variables dichotomised by the median value. Univariate odds ratio (OR) with $95 \%$ confidence intervals (Cl)

\begin{tabular}{|c|c|c|c|c|}
\hline $\begin{array}{l}\text { Predictor variable (values from } \\
\text { baseline)* }\end{array}$ & n† & $\begin{array}{l}\text { Incident OA at } \\
\text { follow up }(n=41)\end{array}$ & $\begin{array}{l}\text { No OA at follow } \\
\text { up }(n=53)\end{array}$ & OR $(95 \% \mathrm{Cl})$ \\
\hline Age (years) & 94 & $48(35-54)$ & $44(35-54)$ & $1.58(0.69$ to 3.60$)$ \\
\hline Sex (women/men) & $39 / 55$ & $18 / 23$ & $21 / 32$ & 0.84 (0.37 to 1.92$)$ \\
\hline Body mass index $\left(\mathrm{kg} / \mathrm{m}^{2}\right)$ & 94 & $25.2(19.3-37)$ & $25.4(18.3-34)$ & $0.96(0.42$ to 2.20$)$ \\
\hline Pain VAS $(0-100) \ddagger$ & 74 & $3(0-51)$ & $0(0-84)$ & $1.33(0.52$ to 3.44$)$ \\
\hline Maximum number of one-leg rises§ & 90 & $17(0-99)$ & $25(1-229)$ & 2.55 (1.08 to 6.02$)$ \\
\hline Time spent walking $300 \mathrm{~m}(\mathrm{~min}) \ddagger$ & 92 & $2.58(1.94-3.67)$ & $2.52(1.93-4.08)$ & $1.67(0.72$ to 3.86$)$ \\
\hline Timed standing on one leg $(s) \S$ & 92 & $15.75(2-31)$ & $18(2-31)$ & $0.98(0.43$ to 2.25$)$ \\
\hline
\end{tabular}

*Variable expressed as median (range), except for sex where numbers are presented; tnumbers of patients included in analysis; †lower value indicates better result; §higher value indicates better result.

It has been suggested that knee pain affects quadriceps strength. ${ }^{26}$ In our study cohort all had chronic knee pain at inclusion, but lower extremity functional performance was not associated with baseline pain. This result is in accordance with previously findings by Slemenda et al. ${ }^{11}$ Furthermore, there was no association in this study between pain at baseline and development of radiographic osteoarthritis.

\section{Critical assessments}

The strengths of the present study are primarily the population based, prospective design, together with the younger age of the cohort. To our knowledge this is the first study of the role of functional performance in developing knee osteoarthritis in young or middle aged subjects. Osteoarthritis treatment today is symptomatic. If we could identify risk factors for osteoarthritis in younger patients, we might have a chance to intervene and influence the development of the disease.

One concern is the validity of the functional tests used. At baseline, in 1990, validated tests of functional performance in osteoarthritis of the lower extremity were lacking. ${ }^{27} 28$ The tests in this study were chosen because of their applicability to clinical situations; they were easy to perform, required no special equipment, and they tested functional performance used in daily situations. In an effort to validate the test of maximum number of one-leg rises, strength was measured on a small number of patients with a hand held dynamometer in knee extension $(\mathrm{n}=47) r_{\mathrm{s}}=0.64, \mathrm{p}=0.0001$ and knee flexion $(\mathrm{n}=46) r_{\mathrm{s}}=0.45, \mathrm{p}=0.01$ (unpublished data).

Table 3 In the group with no radiographic changes at baseline, less endurance in one-leg rise from sitting was a significant predictor of developing incident knee osteoarthritis (OA) 5 years later, controlled for one confounder at a time using logistic regression analyses. Variables dichotomised by the median value

\begin{tabular}{lll}
\hline Predictor & $\mathbf{n}^{*}$ & OR $(95 \% \mathrm{Cl}) \S$ \\
\hline Age† & 90 & $2.48(1.04$ to 5.89$)$ \\
Sex† & 90 & $2.50(1.05$ to 5.95$)$ \\
Body mass index $\dagger$ & 88 & $2.78(1.16$ to 6.67$)$ \\
Pain (VAS) baseline† & 72 & $2.79(1.02$ to 7.68$)$ \\
All above & 70 & $2.67(0.92$ to 7.76$)$ \\
\hline
\end{tabular}

*Number of patients included in each analysis; tbivariate analysis. Only one predictor at a time was included in the logistic regression together with maximum number of one-leg rises, because of the rather small samples; łmaximum number of one-leg rises, controlled for age, sex, body mass index, and pain in multivariate logistic regression; §odds ratio (OR) with $95 \%$ confidence interval $(\mathrm{Cl})$ for the maximum number of oneleg rises (less than $v$ greater than the median).
These associations between dynamometry and functional test are moderate as expected, considering both that the maximum number of one-leg rises is a complex performance, involving several muscle groups as well as coordination, and that the results for the reliability and usefulness of a hand held dynamometer are divergent. ${ }^{29}{ }^{30}$ It is reasonable to think that the other two tests of functional performance-time spent walking 300 metres and timed standing on one legare influenced to a larger extent by other factors and other groups of muscles. If the quadriceps is the most important muscle group for knee joint stability, as stated by Mikesky et $a,_{1}^{13}$ the lower predictability of these two tests, compared with the maximum number of one-leg rises, would be expected, and would further validate our findings. The fact that the maximum number of one-leg rises was not predictive when controlled for age, sex, body mass index, and pain in the same analysis is likely to be explained by the smaller number of patients in that analysis. At the beginning of the data collection, pain was not regularly recorded, which gives fewer available data in analyses including pain. The relatively small number of patients in subgroups, and the within-group variability, contribute to the lack of sufficient statistical power in multivariate analysis. However, the odds ratio in multivariate analysis (OR 2.67, 95\% CI 0.92 to 7.76 ) very clearly points in the same direction as the corresponding odds ratios in the bivariate analyses, as is shown in table 3 . Testing for the maximum number of one-leg rises should be further validated but might be a candidate as a screening test, useful in clinical practice and epidemiological studies.

Another possible concern is the difference in radiographic technique at baseline and follow up. At baseline, radiographs were taken with straight knees, and at follow up a semiflexed position was considered a more reliable radiographic technique, which has later been corroborated. ${ }^{17}{ }^{31}$ Hence, radiographs could not be read "blinded" for their time sequence, although the baseline and follow up radiographs were read at different occasions, and the reader was unaware of all other clinical information. These methodological differences may have affected the occurrence and disappearance of radiographic findings, such as osteophytes. Such misclassification would, however, be non-differential in relation to evaluated predictors and would therefore not bias the results, although it may explain the high incidence of osteoarthritis in this cohort. The relevance of Kellgren and Lawrence grade 1 (minute osteophytes) could also be questioned, but the technique for reading and its relation to other features of osteoarthritis, both on plain radiographs and on magnetic resonance imaging, is well documented. ${ }^{18}$ The validity of our finding of regression of radiographic changes is also supported by other studies ${ }^{19}{ }^{32}$ and by the association between radiographic regression and lower body mass index. The high 
Table 4 There was no significant predictor of radiographic progression 5 years later among those with prevalent knee osteoarthritis (OA) at baseline. Variables dichotomised by the median value. Univariate odds ratio (OR) with $95 \%$ confidence intervals (CI)

\begin{tabular}{|c|c|c|c|c|}
\hline $\begin{array}{l}\text { Predictor variable (values from } \\
\text { baseline) }\end{array}$ & n† & $\begin{array}{l}\text { Progress at follow } \\
\text { up }(n=29)\end{array}$ & $\begin{array}{l}\text { No progress at } \\
\text { follow up }(n=25)\end{array}$ & OR $(95 \% \mathrm{Cl})$ \\
\hline & & & $44(35-54)$ & $1.57(0.53$ to 4.60$)$ \\
\hline en/men) & $23 / 31$ & $11 / 18$ & $12 / 13$ & .51 to 4.47 ) \\
\hline Body ma & 54 & $26.8(21.6-37.5)$ & $24.5(20.2-31)$ & $1.87(0.62$ to 5.63$)$ \\
\hline Pain VAS $(0-100)$ & 53 & $5(0-50)$ & $0(0-20)$ & $2.33(0.66$ to 8.30$)$ \\
\hline Maximum number of one-leg rises§ & 54 & $17(0-140)$ & $22(1-213)$ & $1.33(0.46$ to 3.90$)$ \\
\hline Time spent walking $300 \mathrm{~m}(\mathrm{~min}) \ddagger$ & 53 & $2.45(1.74-4.29)$ & $2.48(2.12-3.33)$ & 0.98 (0.32 to 3.02 ) \\
\hline Timed standing on one leg $(s) \S$ & 54 & $12(2.6-31)$ & $31(2.8-31)$ & $1.56(0.53$ to 4.60$)$ \\
\hline
\end{tabular}

*Variable expressed as median (range), except for sex where numbers are presented; tnumbers of patients included; flower value indicates better result; shigher value indicates better result.

incidence rate in our study may also be explained by the fact that all patients had knee pain at inclusion. It has been suggested that osteophytes are more associated with pain than joint space narrowing. ${ }^{33}$ Possibly, the pain is an early sign of osteoarthritis in many cases, caused by osteophytosis without other signs of objectively verified osteoarthritis.

A third possible concern is missing data from nonattenders. Selection bias could not be excluded. It is not possible to state whether such bias would have strengthened or weakened our findings.

\section{CONCLUSION}

Reduced functional performance in the lower extremity predicted the development of radiographic knee osteoarthritis, mainly osteophytes, five years later in middle aged subjects with chronic knee pain at inclusion, even when controlled for age, sex, body mass index, and pain intensity. This result suggests that functional performance is of importance for the development of knee osteoarthritis. The test of the maximum number of one-leg rises is potentially useful to screen which patients with knee pain are at risk for developing knee osteoarthritis.

\section{ACKNOWLEDGEMENTS}

Grants were received from the Swedish Rheumatism Association in Stockholm, the Swedish Rheumatism Association in Gothenburg, the Department of Research and Development at Spenshult Hospital for Rheumatic Diseases, Halmstad, Sweden, and the Zoega Foundation of Medical Research.

\section{Authors' affiliations}

C A Thorstensson, IF Petersson, L T H Jacobsson, T L Boegård, E M Roos, Spenshult Hospital for Rheumatic Diseases, Oskarström, Sweden L T H Jacobsson, Department of Rheumatology, Malmö University Hospital, Malmö, Sweden

T L Boegård, Department of Radiology, County Hospital, Helsingborg, Sweden

E M Roos, Department of Orthopaedics, Lund University Hospital, Lund, Sweden

\section{REFERENCES}

1 Tzonchev VT, Pilossoff T, Kanev K. Prevalence of osteoarthritis in Bulgaria in population studies of the rheumatic diseases. Amsterdam: Excerpta Medica Foundation, 1968.

2 Basic data on osteoarthritis of the knee, hip and sacroiliac joints in adults aged 25-74 years. USA 1971-75. National Center for Health Statistics: HANES 1, 1979.

3 Williams M, Frankel SJ, Nanchahal K, Coast J, Donovan JL. DHA project: Epidemiologically based needs assessment: Total knee replacement. In: Stevens A, Raferty J, eds. Health needs assessment. Vol 1. Oxford: Raddliffe, 1994:448-523.

4 Hernborg JS, Nilsson BE. Age and sex incidence of osteophytes in the knee joint. Acta Orthop Belg 1973;44:66-8.

5 Petersson IF, Boegard T, Saxne T, Silman AJ, Svensson B. Radiographic osteoarthritis of the knee classified by the Ahlback and Kellgren \& Lawrence systems for the tibiofemoral joint in people aged 35-54 years with chronic knee pain. Ann Rheum Dis 1997;56:493-6.

6 Kellgren J, Lawrence J. The epidemiology of chronic rheumatism. Atlas of standard radiographs. Oxford: Blackwell Scientific, 1963.

7 Hart DJ, Spector TD. Kellgren \& Lawrence grade 1 osteophytes in the kneedoubtful or definite? Osteoarthritis Cartilage 2003;11:149-50.

8 Cooper C, Snow S, McAlindon TE, Kellingray S, Stuart B, Coggon D, et al. Risk factors for the incidence and progression of radiographic knee osteoarthritis. Arthritis Rheum 2000;43:995-1000.

9 Hurley MV. The role of muscle weakness in the pathogenesis of osteoarthritis. Rheum Dis Clin North Am 1999;25:283-98.

10 Hurley MV, Scott DL, Rees J, Newham DJ. Sensorimotor changes and functional performance in patients with knee osteoarthritis. Ann Rheum Dis 1997:56:641-8.

11 Slemenda C, Heilman DK, Brandt KD, Katz BP, Mazzuca SA, Braunstein EM, et al. Reduced quadriceps strength relative to body weight: a risk factor for knee osteoarthritis in women? Arthritis Rheum 1998;41:1951-9.

12 Radin EL, Paul IL, Rose RM. Role of mechanical factors in pathogenesis of primary osteoarthritis. Lancet 1972;i:519-22.

13 Mikesky AE, Meyer A, Thompson KL. Relationship between quadriceps strength and rate of loading during gait in women. J Orthop Res 2000; 18:171-5.

14 Larsson AC, Petersson I, Ekdahl C. Functional capacity and early radiographic osteoarthritis in middle-aged people with chronic knee pain. Physiother Res Int 1998;3:153-63.

15 Fransen M, Crosbie J, Edmonds J. Reliability of gait measurements in people with osteoarthritis of the knee. Phys Ther 1997;77:944-53.

16 Ekdahl C, Jarnlo GB, Andersson SI. Standing balance in healthy subjects. Evaluation of a quantitative test battery on a force platform. Scand J Rehabil Med 1989;21:187-95.

17 Boegard T, Rudling O, Petersson IF, Sanfridsson J, Saxne T, Svensson B, et al. Postero-anterior radiogram of the knee in weight-bearing and semiflexion. Comparison with MR imaging. Acta Radiol 1997;38:1063-70.

18 Boegard T, Rudling O, Petersson IF, Jonsson K. Correlation between radiographically diagnosed osteophytes and magnetic resonance detected cartilage defects in the tibiofemoral joint. Ann Rheum Dis 1998;57:401-7.

19 Spector TD, Dacre JE, Harris PA, Huskisson EC. Radiological progression of osteoarthritis: an 11 year follow up study of the knee. Ann Rheum Dis 1992;51:1107-10.

20 Bland M. An introduction to medical statistics, 3rd ed. Oxford: Oxford University Press, 2000.

21 Deyle GD, Henderson NE, Matekel RL, Ryder MG, Garber MB, Allison SC. Effectiveness of manual physical therapy and exercise in osteoarthritis of the knee. A randomized, controlled trial. Ann Intern Med 2000;132:173-81.

22 Wolfe F, Lane NE. The longterm outcome of osteoarthritis: rates and predictors of joint space narrowing in symptomatic patients with knee osteoarthritis. J Rheumatol 2002;29:139-46.

23 Brandt KD, Heilman DK, Slemenda C, Katz BP, Mazzuca SA, Braunstein EM, et al. Quadriceps strength in women with radiographically progressive osteoarthritis of the knee and those with stable radiographic changes. J Rheumatol 1999;26:2431-7.

24 Hart DJ, Doyle DV, Spector TD. Incidence and risk factors for radiographic knee osteoarthritis in middlle-aged women: the Chingford Study. Arthritis Rheum 1999;42:17-24.

25 Oliveria SA, Felson DT, Cirillo PA, Reed JI, Walker AM. Body weight, body mass index, and incident symptomatic osteoarthritis of the hand, hip, and knee. Epidemiology 1999;10:161-6.

26 O'Reilly SC, Jones A, Muir KR, Doherty M. Quadriceps weakness in knee osteoarthritis: the effect on pain and disability. Ann Rheum Dis 1998;57:588-94.

27 Lankhorst GJ, Van de Stadt RJ, Van der Korst JK. The relationships of functional capacity, pain, and isometric and isokinetic torque in osteoarthrosis of the knee. Scand J Rehabil Med 1985;17:167-72.

28 Minor MA, Hewett JE, Webel RR, Dreisinger TE, Kay DR. Exercise tolerance and disease related measures in patients with rheumatoid arthritis and osteoarthritis. J Rheumatol 1988;15:905-11. 
29 Reed RL, Den Hartog R, Yochum K, Pearlmutter L, Ruttinger AC, Mooradian AD. A comparison of hand-held isometric strength measurement with isokinetic muscle strength measurement in the elderly. J Am Geriatr Soc 1993:41:53-6.

30 Deones VL, Wiley SC, Worrell T. Assessment of quadriceps muscle performance by a hand-held dynamometer and an isokinetic dynamometer. J Orthop Sports Phys Ther 1994;20:296-301.

31 Buckland-Wright JC, Wolfe F, Ward RJ, Flowers N, Hayne C. Substantial superiority of semiflexed (MTP) views in knee osteoarthritis: a comparative radiographic study, without fluoroscopy, of standing extended, semiflexed (MTP), and schuss views. J Rheumatol 1999;26:2664-74.

32 Boegard TL, Rudling O, Petersson IF, Jonsson K. Magnetic resonance imaging of the knee in chronic knee pain. A 2-year follow-up. Osteoarthritis Cartilage $2001 ; 9: 473-80$

33 Lanyon P, O'Reilly S, Jones A, Doherty M. Radiographic assessment of symptomatic knee osteoarthritis in the community: definitions and normal joint space. Ann Rheum Dis 1998;57:595-601.

\section{$\mathrm{ECHO}$}

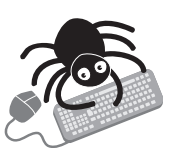

Please visit the Annals of the Rheumatic Diseases website [www. annrheumdis. com] for a link to the full text of this article.
Rapid ELISA for PR3- and MPO-ANCA is a reliable emergency screen for small vessel vasculitis

A

rapid test for serological markers of small vessel vasculitis developed for urgent assessment is as reliable as recommended tests, according to an audit in a regional immunology laboratory in the UK. The rapid enzyme linked immunosorbent assays (ELISAs) for proteinase 3 (PR3) and myeloperoxidase (MPO) antineutrophil cytoplasmic antibodies (ANCA) are therefore suitable for emergency testing in suspected small vessel vasculitis in acute renal failure, pulmonary renal syndrome, and mononeuritis multiplex.

Good agreement was observed between the rapid (qualitative) PR3/MPO-ANCA ELISA and the international standard indirect immunofluorescence (IIF) test, with a reported sensitivity of $82 \%$, specificity $97 \%$, positive predictive value $92 \%$, and negative predictive value $93 \%$. Similar results were obtained between rapid PR3-ANCA ELISA and its standard quantitative ELISA counterpart (sensitivity $87 \%$, specificity $93 \%$, positive predictive value $93 \%$, negative predictive value $88 \%$ ), and complete correlation occurred between the rapid and quantitative MPO-ANCA ELISAs. Positive results in rapid and quantitative ELISAs correlated with small vessel vasculitis in all cases for which biopsy specimens were available (14 PR3-ANCA, 8 MPO-ANCA).

The audit screened serum from 103 consecutive patients over 12 months with rapid PR3and MPO-ANCA ELISA and further tested positive samples with standard IIF and ELISA tests for ANCA. Clinical records were available for 31 of 34 patients with positive results on any test and biopsy specimens for 22 .

Rapid PR3- and MPO-ANCA ELISAs are widely used in diagnostic laboratories to determine vasculitis in urgent situations but have not before been formally tested against the recommended standardised IIF and quantitative ELISA.

A Journal of Clinical Pathology 2003;56;775-777. 